\title{
Direct torque control of doubly star induction machine fed by voltage source inverter using type-2 fuzzy logic speed controller
}

\author{
Lallouani Hellali*, Saad Belhamdi, Benyettou Loutfi, Reghioui Hassen \\ Laboratory of Electrical Engineering, Department of Electrical Engineering, Faculty of Technology, University Mohamed \\ Boudiaf of M'sila, 28000, Algeria
}

Corresponding Author Email: hellali.alouani@univ-msila.dz

https://doi.org/10.18280/ama_c.730410

Received: 16 July 2018

Accepted: 15 November 2018

\section{Keywords:}

doubly star induction machine (DSIM),

Inverter, type-2 fuzzy logic controller

(T2FLC), direct torque control (DTC)

\begin{abstract}
This paper concerns the study of a direct torque control based on fuzzy logic type-2 for the speed regulation of a doubly star Induction Machine fed by voltage source inverter. This command has become one of the high performance control strategies for AC machine to supply a very rapid torque and flux control. The proposed technique consists to change the proportional and integral controllers by type- 2 fuzzy logic controller. The performance of the scheme in different operating conditions is studied. Particular interest is given to the robustness of the fuzzy logic based control. Furthermore, the simulation results illustrate the efficiency and robustness of the type-2 fuzzy logic controller.
\end{abstract}

\section{INTRODUCTION}

The doubly star induction machine is demanded in aerospace applications and electric/hybrid vehicles, cement mills, rolling mills, mine hoists ... etc (Zhao, 1995, Tir, 2016). Because this machine offers various advantages over conventional three-phase machines, such as minimize the amplitude and increasing the frequency of torque pulsation, minimize the current per phase, increasing the voltage per phase, reducing the rotor harmonic currents, and high reliability [1].

The control of the DSIM has progressed significantly in recent times; particularly with the direct torque control method was proposed in the middle of 1980 by I. Takahashi [5]. The DTC used the errors between the estimated and the reference values of flux nad torque in order to minimize the flux and torque errors within the band limits. This method is enabling us to directly control the inverter states [9].

Today, Fuzzy logic is a technique used in artificial intelligence and with widely used in different areas including: control, automation... etc. And the type-2 fuzzy logic has been attracting great research interests because are powerful tools and better able to handle uncertainties than their type- 1 in complex processes $[11,14]$. Does not need a detailed model [13]. Type-2 fuzzy logic controllers are one of useful control schemes to adjust the speed stabilization of DSIM. In this paper the type-2 fuzzy logic controller is developed and is investigated for a direct torque control of doubly star induction machine. For evaluates the performance index of the system as integral time-weighted absolute error (ITAE), integral absolute error (IAE), and integral squared error (ISE), for the proposed scheme (type-2 fuzzy logic controller) and is compared with the other controller i.e. the type-1 fuzzy logic.

This paper is structured as follows: In Section 2 the model of the DSIM is presented, and the model mathematical of VSI is presented in Section 3. Next, we will describe the direct torque control by a Type- 2 fuzzy logic controller; the designed DTC models are introduced and explained, in order to improve the static and dynamic control performance of the DSIM in section 4 and 5. Section 6 shows simulation results for the performances of T2FLC speed controller of DTC-DSIM under various conditions operation. Finally, a general conclusion summary this work.

\section{MATHEMATICAL MODEL OF DSIM}

The double star induction machine represented by two stators windings: which are displaced by $30^{\circ}$ electrical angle and the rotor windings are sinusoidal distributed and have axes that are displaced apart by $120^{\circ}$ [4].

The assumptions used for the model of this machine are the following: The magnetic saturation and core losses are neglected, Motor windings are sinusoidal distributed, and the two stars have same parameters, and the flux path is linear [6], the windings of the DSIM are shown in Figure. 1

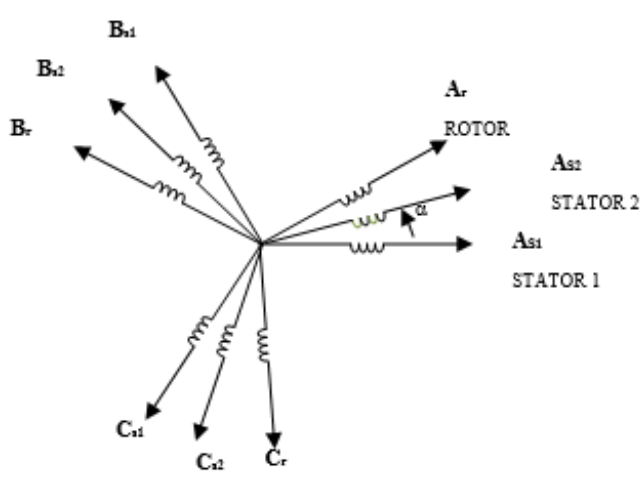

Figure 1. DSIM winding representation

The voltage equations of the DSIM have the following matrix form [7]: 
$\left[V_{\mathrm{s} 1, \mathrm{abc}}\right]=\left[\mathrm{R}_{\mathrm{s} 1}\right]\left[i_{\mathrm{s} 1, \mathrm{abc}}\right]+\frac{\mathrm{d}}{\mathrm{dt}}\left[\psi_{\mathrm{s} 1, \mathrm{abc}}\right]$

$\left[V_{\mathrm{s} 2, \mathrm{abc}}\right]=\left[\mathrm{R}_{\mathrm{s} 2}\right]\left[i_{\mathrm{s} 2, \mathrm{abc}}\right]+\frac{\mathrm{d}}{\mathrm{dt}}\left[\psi_{\mathrm{s} 2, \mathrm{abc}}\right]$

$0=\left[\mathrm{R}_{\mathrm{r}}\right]\left[i_{\mathrm{r}, \mathrm{abc}}\right]+\frac{\mathrm{d}}{\mathrm{dt}}\left[\psi_{\mathrm{r}, \mathrm{abc}}\right]$

With

$V_{\mathrm{s} 1, \mathrm{abc}}, V_{\mathrm{s} 2, \mathrm{abc}}$ : Stator voltages; $i_{\mathrm{s} 1, \mathrm{abc}}, i_{\mathrm{s} 2, \mathrm{abc}}, i_{\mathrm{r}, \mathrm{abc}}$ : Stator and rotor currents;

$\psi_{\mathrm{s} 1, \mathrm{abc}}, \psi_{\mathrm{s} 2, \mathrm{abc}}, \psi_{\mathrm{r}, \mathrm{abc}}:$ Stator and rotor flux; $\left[R_{\mathrm{s} 1}\right],\left[R_{\mathrm{s} 2}\right]$, $\left[R_{r}\right]$ : Resistance matrices stator and rotor .

To ensure the control, the DSIM model expressed in $(\alpha-\beta)$ axes presented by [3]:

$\dot{X}=A X+B U$

With,

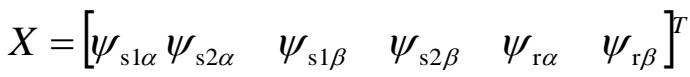

$U=\left[\begin{array}{llllll}V_{\mathrm{s} 1 \alpha} V_{\mathrm{s} 2 \alpha} & V_{\mathrm{s} 1 \beta} & V_{\mathrm{s} 2 \beta} & 0 & 0\end{array}\right]^{T}$

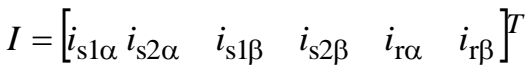

where:

$V_{\mathrm{s} 1, \alpha \beta}, V_{\mathrm{s} 2, \alpha \beta}$ : Stator voltages $\alpha-\beta$ components; $i_{\mathrm{s} 1, \alpha \beta}, i_{\mathrm{s} 2, \alpha \beta}$, $i_{\mathrm{r}, \alpha \beta}$ : Stator and Rotor currents $\alpha-\beta$ components; $\psi_{\mathrm{s} 1, \alpha \beta}$, $\psi_{\mathrm{s} 2, \alpha \beta}, \psi_{\mathrm{r}, \alpha \beta}$ : Stator and Rotor flux $\alpha-\beta$ components.

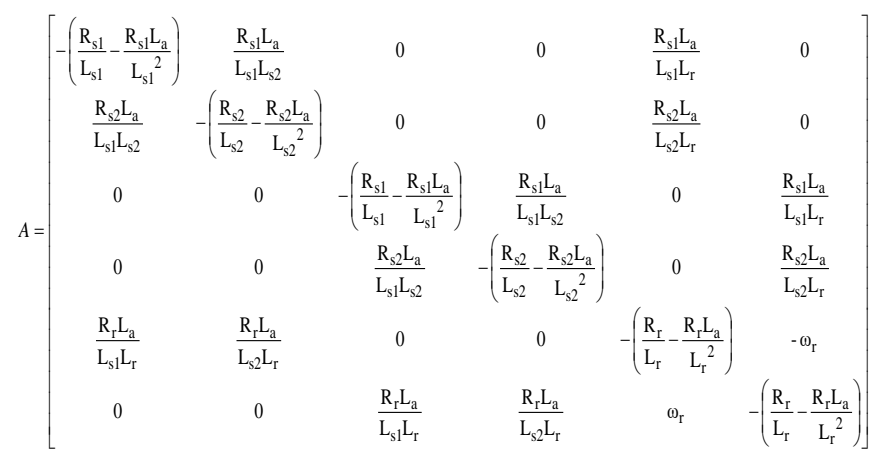

and

$$
[A]=\left[A_{11}\right]+\left[A_{12}\right] \omega_{\mathrm{r}}
$$$$
\left[A_{12}\right]=\left[\begin{array}{cccccc}
0 & 0 & 0 & 0 & 0 & 0 \\
0 & 0 & 0 & 0 & 0 & 0 \\
0 & 0 & 0 & 0 & 0 & 0 \\
0 & 0 & 0 & 0 & 0 & 0 \\
0 & 0 & 0 & 0 & 0 & -1 \\
0 & 0 & 0 & 0 & 1 & 0
\end{array}\right]
$$

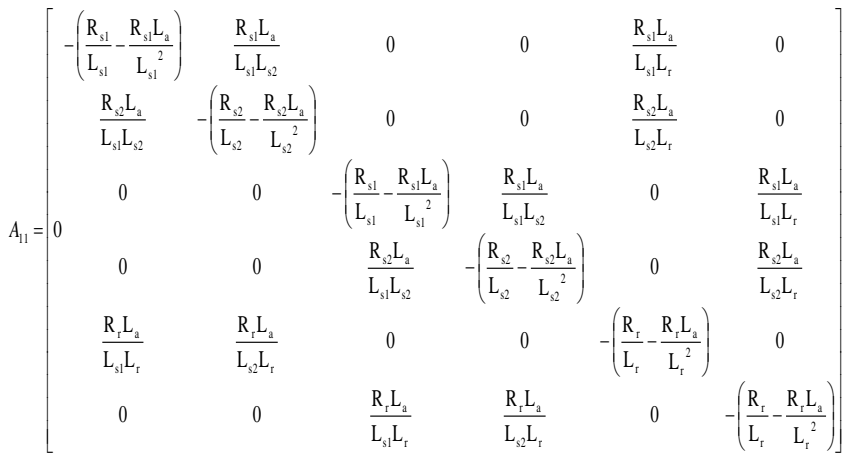

The relations enter the flux and the current are [1]:

$$
\left\{\begin{array}{l}
\psi_{\mathrm{s} 1 \alpha}=\mathrm{L}_{\mathrm{s} 1} i_{\mathrm{s} 1 \alpha}+\mathrm{L}_{\mathrm{m}}\left(i_{\mathrm{s} 1 \alpha}+i_{\mathrm{s} 2 \alpha}+i_{\mathrm{r} \alpha}\right) \\
\psi_{\mathrm{s} 1 \beta}=\mathrm{L}_{\mathrm{s} 1} i_{\mathrm{s} 1 \beta}+\mathrm{L}_{\mathrm{m}}\left(i_{\mathrm{s} 1 \beta}+i_{\mathrm{s} 2 \beta}+i_{\mathrm{r} \beta}\right) \\
\psi_{\mathrm{s} 2 \alpha}=\mathrm{L}_{\mathrm{s} 2} i_{\mathrm{s} 2 \alpha}+\mathrm{L}_{\mathrm{m}} i\left(i_{\mathrm{s} 1 \alpha}+i_{\mathrm{s} 2 \alpha}+i_{\mathrm{r} \alpha}\right) \\
\psi_{\mathrm{s} 2 \beta}=\mathrm{L}_{\mathrm{s} 2} i_{\mathrm{s} 1 \beta}+\mathrm{L}_{\mathrm{m}}\left(i_{\mathrm{s} 1 \beta}+i_{\mathrm{s} 2 \beta}+i_{\mathrm{r} \beta}\right) \\
\psi_{\mathrm{r} \alpha}=\mathrm{L}_{\mathrm{r}} i_{\mathrm{r} \alpha}+\mathrm{L}_{\mathrm{m}}\left(i_{\mathrm{s} 1 \alpha}+i_{\mathrm{s} 2 \alpha}+i_{\mathrm{r} \alpha}\right) \\
\psi_{\mathrm{r} \beta}=\mathrm{L}_{\mathrm{r}} i_{\mathrm{r} \beta}+\mathrm{L}_{\mathrm{m}}\left(i_{\mathrm{s} 1 \beta}+i_{\mathrm{s} 2 \beta}+i_{\mathrm{r} \beta}\right)
\end{array}\right.
$$

where:

$\mathrm{L}_{\mathrm{m}}$ : Cyclic mutual inductance between stator 1, stator 2 and rotor; $\mathrm{L}_{\mathrm{s} 1}, \mathrm{~s} 2, \mathrm{r}$ : the inductance of a stator 1 , stator 2 and rotor respectively; $\mathrm{L}_{\mathrm{s} 1}+\mathrm{L}_{\mathrm{m}}, \mathrm{L}_{\mathrm{s} 2}+\mathrm{L}_{\mathrm{m}}, \mathrm{L}_{\mathrm{r}}+\mathrm{L}_{\mathrm{m}}$ : the total inductance of a stator 1, stator 2 and rotor respectively.

The electromagnetic torque and the mechanical equations can be written as:

$$
\begin{aligned}
& T_{e m}=\mathrm{p} \frac{\mathrm{L}_{\mathrm{m}}}{\mathrm{L}_{\mathrm{m}}+\mathrm{L}_{\mathrm{r}}}\left(\psi_{\mathrm{r} \alpha}\left(i_{\mathrm{s} 1 \beta}+i_{\mathrm{s} 2 \beta}\right)-\psi_{\mathrm{r} \beta}\left(i_{\mathrm{s} 1 \alpha}+i_{\mathrm{s} 2 \alpha}\right)\right) \\
& \mathrm{J} \frac{\mathrm{d} \Omega}{\mathrm{dt}}=T_{e m}-T_{r}-K_{f} \Omega
\end{aligned}
$$

\section{VOLTAGE SOURCE INVERTER}

The voltage source inverter (VSI) is a static converter constituted by switching cells generally with IGBT for high powers. The operating principle can be expressed by imposing on the machine the voltages with variable amplitude and frequency starting from a standard network.

The mathematical model of VSI presented by:

$$
\left[\begin{array}{l}
V_{a} \\
V_{b} \\
V_{c}
\end{array}\right]=\left[\begin{array}{ccc}
2 & -1 & -1 \\
-1 & 2 & -1 \\
-1 & -1 & 2
\end{array}\right]\left[\begin{array}{l}
S_{a} \\
S_{b} \\
S_{c}
\end{array}\right]
$$

\section{DIRECT TORQUE CONTROL}

The objective of direct torque control is a based on the switching tables with hysteresis of torque and stator flux. The reference values of flux $\left(\psi_{s}\right)$ and torque $\left(T_{\mathrm{em}}\right)$ are compared to their actual values and the resultant errors are fed into a two level hysteresis comparator for the flux and three level hysteresis comparator for the torque, who allows controlling 
the motor in the two directions of rotation (figure.2). Using this method, for the minimization of the commutations of the inverter switches, on the torque/stator flux decoupling, on the control of the PWM generator. This particularity defines the DTC as an adapted control technique of AC machines $[9,16]$.
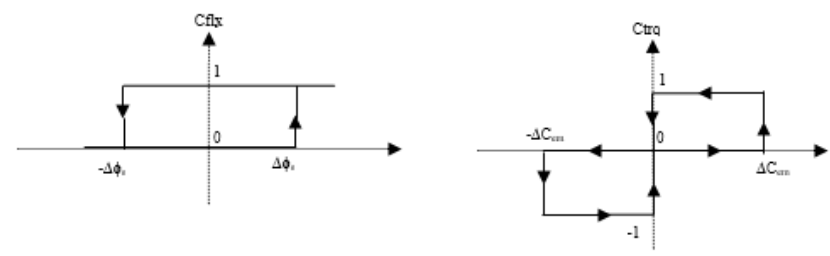

Figure 2. Hysteresis comparator, (a): two level hysteresis comparator for the flux, (b): three level hysteresis comparator for the torque

The principle of direct torque control operation explained by analyzing the stator voltage equation in the stator flux reference frame [16]:

$\psi_{\mathrm{s} 1 \alpha e s t}=\int_{0}^{T_{e}}\left(V_{\mathrm{s} 1 \alpha}-\mathrm{R}_{\mathrm{s} 1} i_{\mathrm{s} 1 \alpha}\right) d t+\psi_{\mathrm{s} 0}$

$\psi_{\mathrm{s} 1 \beta e s t}=\int_{0}^{T_{e}}\left(V_{\mathrm{s} 1 \beta}-\mathrm{R}_{\mathrm{s} 1} i_{\mathrm{s} 1 \beta}\right) d t+\psi_{\mathrm{s} 0}$

$\psi_{\mathrm{s} 2 \alpha e s t}=\int_{0}^{T_{e}}\left(V_{\mathrm{s} 2 \alpha}-\mathrm{R}_{\mathrm{s} 1} i_{\mathrm{s} 2 \alpha}\right) d t+\psi_{\mathrm{s} 0}$

$\psi_{\mathrm{s} 2 \beta e s t}=\int_{0}^{T_{e}}\left(V_{\mathrm{s} 2 \beta}-\mathrm{R}_{\mathrm{s} 1} i_{\mathrm{s} 2 \beta}\right) d t+\psi_{\mathrm{s} 0}$

During the switching interval $[0-\mathrm{Te}], V_{\mathrm{s}}>>R_{s} i_{s}$ we can express:

$\psi_{s}(t)=\psi_{\mathrm{s} 0}+V_{\mathrm{s}} T_{e}$

The selected of the voltage vector will be applied to the DSIM at the end of the sample time, as are exposed in (11). by neglecting the stator resistances equation (11) implies that the ends of the stator flux vectors will moves in the direction of the applied voltage vectors as shown in this figure.
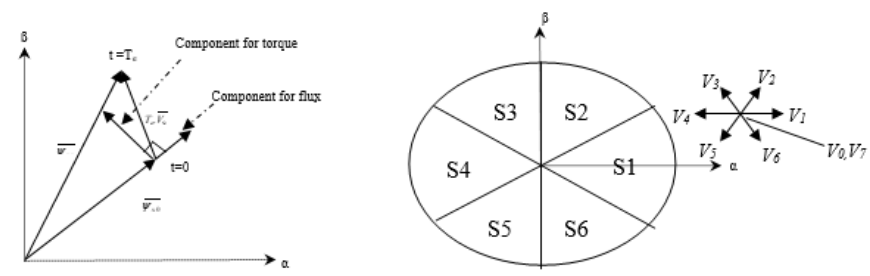

Figure 3. (a): Stator flux vector deviation, (b): Voltage vector selection

\subsection{Stator flux estimation}

The magnitude of stator flux, which can be estimated as following [16]: $\overline{\psi_{\text {sest }}}=\int_{0}^{T_{e}}\left(\overline{V_{\mathrm{s}}}-\mathrm{R}_{\mathrm{s}} \overline{i_{\mathrm{s}}}\right) d t$

The stator flux linkage phases are given by:

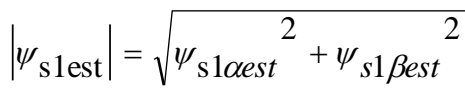

$$
\begin{aligned}
& \left|\psi_{\text {s2est }}\right|=\sqrt{\psi_{s 2 \alpha e s t}^{2}+\psi_{\text {s } 2 \beta e s t}}
\end{aligned}
$$

The stator flux linkage phase's positions are:

$$
\begin{aligned}
& \theta_{\text {s1est }}=\operatorname{arctg}\left(\frac{\psi_{\text {s1 } 1 \text { est }}}{\psi_{\mathrm{s} 1 \alpha e s t}}\right) \\
& \theta_{\text {s2est }}=\operatorname{arctg}\left(\frac{\psi_{\mathrm{s} 2 \beta e s t}}{\psi_{\mathrm{s} 2 \alpha e s t}}\right)
\end{aligned}
$$

The electromagnetic torque expressions are given by:

$$
\begin{aligned}
& T_{\text {em1est }}=\mathrm{p}\left(\psi_{\mathrm{s} 1 \alpha e s t} i_{\mathrm{s} 1 \beta}-\psi_{\mathrm{s} 1 \beta e s t} i_{\mathrm{s} 1 \alpha}\right) \\
& T_{\text {em2est }}=\mathrm{p}\left(\psi_{\mathrm{s} 2 \alpha e s t} i_{\mathrm{s} 2 \beta}-\psi_{\mathrm{s} 2 \beta e s t} i_{\mathrm{s} 2 \alpha}\right) \\
& T_{\text {emest }}=\Gamma_{\text {em1est }}+\Gamma_{\text {em } 2 \text { est }} \\
& T_{\text {emest }}=\mathrm{p}\left(\begin{array}{c}
\left(\psi_{\mathrm{s} 1 \alpha e s t} i_{\mathrm{s} 1 \beta^{-}} \psi_{\mathrm{s} 1 \beta e s t} i_{\mathrm{s} 1 \alpha}\right) \\
+\left(\psi_{\mathrm{s} 2 \alpha e s t} i_{\mathrm{s} 2 \beta}-\psi_{\mathrm{s} 2 \beta e s t} i_{\mathrm{s} 2 \alpha}\right)
\end{array}\right)
\end{aligned}
$$

\subsection{Elaboration of the switching table}

For the selection of the switching state of the inverter used a switching table based on the hysteresis comparators (Cflx, Ctrq) and the sector where is the stator vector flux $\left(\psi_{s}\right)$ in the plan $(\alpha-\beta)$, in order to maintain the magnitude of electromagnetic torque and stator flux interior the hysteresis bands [9].

Table 1. Switching table with zero voltage vectors

\begin{tabular}{cccccccc}
\hline \multicolumn{2}{c}{ Sectors } & 1 & 2 & 3 & 4 & 5 & 6 \\
& & & & & & & \\
\hline \multirow{4}{*}{$\mathrm{Cflx}=1$} & $\mathrm{Ctrq}=1$ & $V_{2}$ & $V_{3}$ & $V_{4}$ & $V_{5}$ & $V_{6}$ & $V_{1}$ \\
& $\mathrm{Ctrq}=0$ & $V_{7}$ & $V_{0}$ & $V_{7}$ & $V_{0}$ & $V_{7}$ & $V_{0}$ \\
& $\mathrm{Ctrq}=-1$ & $V_{6}$ & $V_{1}$ & $V_{2}$ & $V_{3}$ & $V_{4}$ & $V_{5}$ \\
& $\mathrm{Ctrq}=1$ & $V_{3}$ & $V_{4}$ & $V_{5}$ & $V_{6}$ & $V_{1}$ & $V_{2}$ \\
$\mathrm{Cflx}=0$ & $\mathrm{Ctrq}=0$ & $V_{0}$ & $V_{7}$ & $V_{0}$ & $V_{7}$ & $V_{0}$ & $V_{7}$ \\
& $\mathrm{Ctrq}=-1$ & $V_{5}$ & $V_{6}$ & $V_{1}$ & $V_{2}$ & $V_{3}$ & $V_{4}$ \\
\hline
\end{tabular}

where: $V_{0}(000), V_{7}(111), V_{1}(100), V_{2}(110), V_{3}(010), V_{4}(011)$, $V_{5}(001), V_{6}(101)$.

Table 1 shows the sequences corresponding to each position, which selects the optimal switching state $S_{a}, S_{b}, S_{c}$.

For example: 
- if stator flux lies in sector 1, Ctrq is positive and Cflx is Positive then the motor has to accelerate to reduce the art quickly vector $V_{2}$ is applied which rotates the flux in clockwise direction.

- If stator flux lies in sector $1, \mathrm{Ctrq}$ is negative and Cflx is positive, then the motor has to decelerate vector $V_{6}$ is applied which rotates the flux in anti clockwise direction.

\section{TYPE-2 FUZZY LOGIC CONTROLLERS}

Type-2 fuzzy sets are more difficult to use compared that type-1 fuzzy sets, the fuzzy inference system (FIS) is a rulebased system that uses fuzzy logic instead of Boolean logic. Type-2 fuzzy set let us to model and to minimize the effects of uncertainties in rule of the system fuzzy logic. Its basic structure has four components (figure 4) [17, 18].

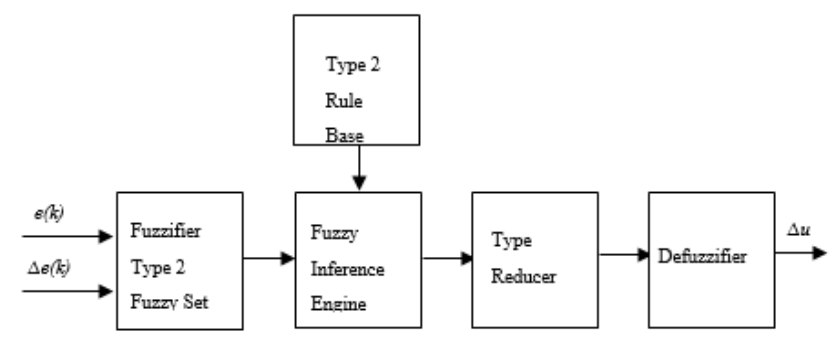

Figure 4. Components of PI Type-2 FLC

The inputs of the T2FLC are the error rotor speed and its variation.

$e(k)=\omega_{\text {ref }}(k)-\omega_{\mathrm{r}}(k)$

$\Delta e(k)=e(k)-e(k-1)$

Figure 5 show the structure of a control based on type-2 fuzzy logic [17]:

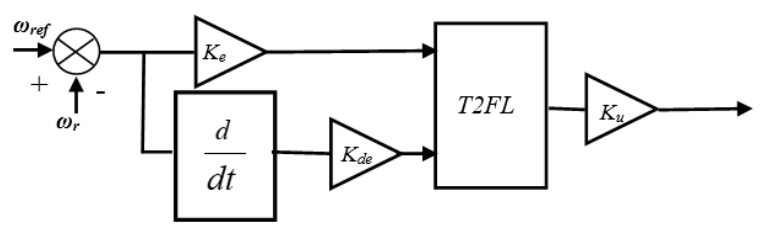

Figure 5. Bloc diagram of T2FLC

Fuzzy logic type-2 system includes 4 components [17].

\subsection{Fuzzification}

Convert classical data or crisp data (e and de) into fuzzy data or Membership Functions (MFs) such as NB (Negative Big), $\mathrm{N}$ (Negative), Z (Zero), P (Positive) and PB (Positive Big) shows in figure 6 [17]:

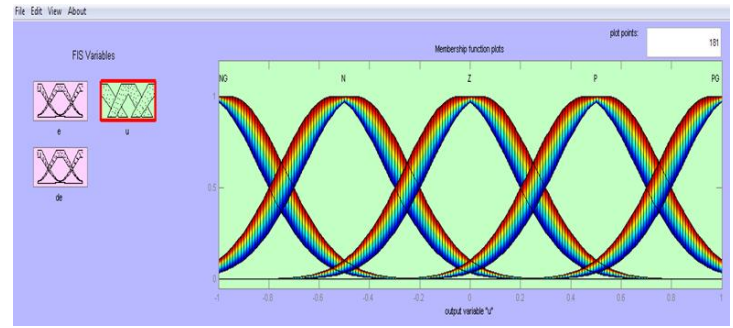

Figure 6. The Type-2 fuzzy membership functions of error speed $e$ and change in error speed de and output variable $\mathrm{u}$

\subsection{Fuzzy inference engine}

One need combines the Membership Functions with the control rules to derive the control output, and arrange those outputs into a table called the lookup table. The control rule is the core of the fuzzy inference process, and those rules are directly related to a human being's intuition and feeling [18].

Rule 1: if e is NB, and de is NB, then $\mathrm{U}$ is $\mathrm{NB}$.

Rule 2: if e is NB, and de is $\mathrm{N}$, then $\mathrm{U}$ is NB.

Rule 25: if e is $\mathrm{PB}$, and de is $\mathrm{PB}$, then $\mathrm{U}$ is $\mathrm{PB}$.

The rule base is as listed in table 2 .

Table 2. Rule base of type 2 fuzzy logic

\begin{tabular}{|c|c|c|c|c|c|c|}
\hline \multicolumn{2}{|c|}{$\Delta \mathrm{u}$} & \multicolumn{5}{|c|}{$\mathrm{e}$} \\
\hline \multirow{6}{*}{$\Delta \mathrm{e}$} & & NB & $\mathrm{N}$ & $\mathrm{Z}$ & $P$ & $\mathrm{~PB}$ \\
\hline & NB & NB & NB & $\mathrm{N}$ & $\mathrm{N}$ & Z \\
\hline & $\mathrm{N}$ & NB & $\mathrm{N}$ & $\mathrm{N}$ & Z & PB \\
\hline & Z & $\mathrm{N}$ & $\mathrm{N}$ & Z & $\mathrm{P}$ & PB \\
\hline & $\mathrm{P}$ & $\mathrm{N}$ & Z & $\mathrm{P}$ & $\mathrm{P}$ & PB \\
\hline & PB & Z & $\mathrm{P}$ & $P$ & PB & PB \\
\hline
\end{tabular}

\subsection{Type reducer}

The type-reducer generates a type-1 fuzzy set output, which is then converted in a numeric output through running the defuzzifier. This type-1 fuzzy set is also an interval set, for the case of our fuzzy logic system we used center of sets (cos) type reduction, $y_{\cos }(\mathrm{x})$, which is expressed as [14]:

$$
\begin{aligned}
& y_{\cos }(x)=\left[y_{u}, y_{l}\right] \\
& y_{u}(x)=\frac{\sum_{i=1}^{M} f_{u}^{i} y_{u}^{i}}{\sum_{i=1}^{M} f_{u}^{i}} \\
& y_{l}(x)=\frac{\sum_{i=1}^{M} f_{l}^{i} y_{l}^{i}}{\sum_{i=1}^{M} f_{l}^{i}}
\end{aligned}
$$

where:

$f_{u}^{i}, f_{l}^{i}$ : area of $i_{\text {th }}$ high and inferior output membership function,

$y_{u}^{i}, y_{l}^{i}$ : centroid of $i_{t h}$ high and inferior output membership function.

\subsection{Defuzzification}

From the type-reducer, we obtain an interval set $y_{\text {cos }}$, to defuzzify it we use the average of $y_{1}$ and $y_{\mathrm{r}}$, so the defuzzified output of an interval singleton type-2 fuzzy logic system is [13]: 


$$
y(x)=\frac{y_{u}(x)+y_{l}(x)}{2}
$$

The block diagram of the fuzzy logic type-2 for the DTC approach of the DSIM is shown in figure 7.

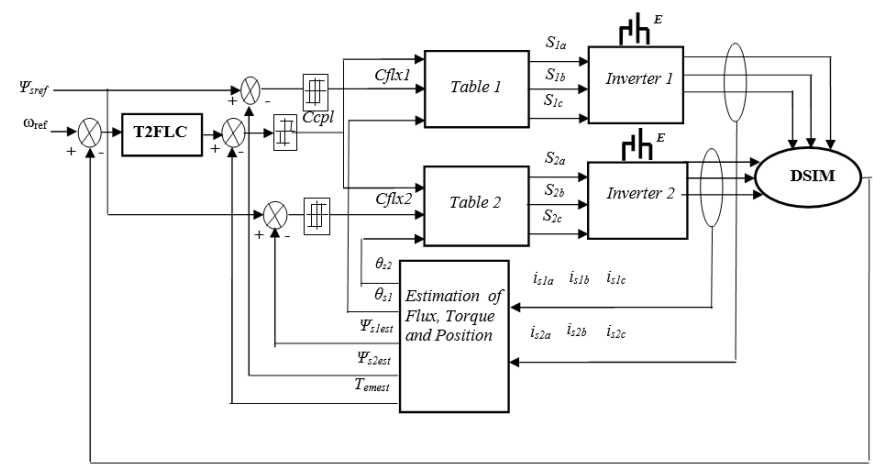

Figure 7. Schema global of DTC using T2FLC for DSIM

\section{RESULTS AND DISCUSSION}

The proposed scheme has been implemented with Matlab/ Simulink in order to evaluate its performance. The parameters of the DSIM are summarized in Appendix. The robustness of the Direct Torque Control using T2FLC of the DSIM is visualized for two tests: the first is the load torque variation; the second is the change of speed and load torque variation.

\subsection{Load torquze variation}

In first test the Torque variation with the sign of resistant torque $T_{r}=14$ N.m for the period of the interval (1.5-3) s, and the DSIM runs with speed values $150 \mathrm{rad} / \mathrm{s}$.
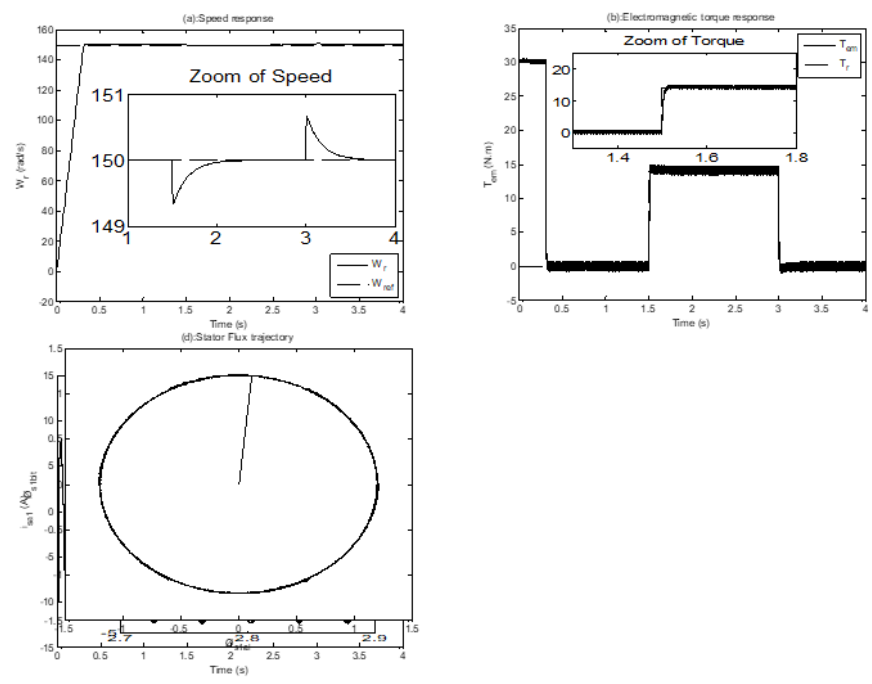

Figure 8. Speed, torque, current stator and park trajectory characteristic of direct torque control with T2FLC Controller, at variation in load torque

The speed reaches its reference value $(150 \mathrm{rad} / \mathrm{s})$ after $(0.4 \mathrm{~s})$ without overtaking. At $\mathrm{t}=(1.5-3) \mathrm{s}$, we applied a load torque $(14$ N.m), the stator current increase $(4.3 \mathrm{~A})$ and the machine developed an electromagnetic torque for compensate the load torque, it reaches at starting $(30$ N.m). The excellent dynamic performance of stator field is evident.

\subsection{Robustness test}

In next test the load torque is applied at $(1-1.5) \mathrm{s} T_{r}=7 \mathrm{~N} . \mathrm{m}$, (2.5-4) s $T_{r}=14 \mathrm{~N} . \mathrm{m}$, and the DSIM runs with speed variation values $[150 \mathrm{rad} / \mathrm{s}$ during $(0-1) \mathrm{s}, 100 \mathrm{rad} / \mathrm{s}$ for the duration of $(1-2.5) \mathrm{s}$ and

$50 \mathrm{rad} / \mathrm{s}$ at $(2.5-4) \mathrm{s}]$.
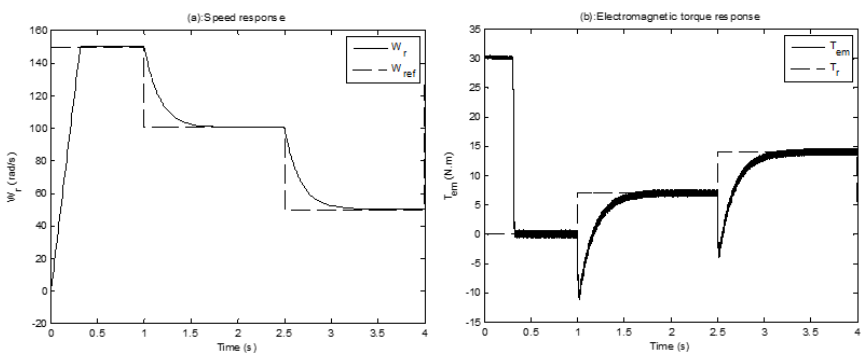

Figure 9. Speed, Electromagnetic torque characteristic of direct torque control with T2FLC Controller, at changes in Speed and load torque variation

Figure 9. illustrate the change in command speed and the load torque is realized. The rotor speed obtained by the T2FLC track very quickly the desired reference speed and the motor output torque will increase to cover this load Figure 9 (a), (b). This test has for object the study of controller behaviors in pursuit and in regulation.

\subsection{Performances evaluate}

For judge the performance of the controllers utilized ITAE, $I A E$ and $I S E$ criterion is widely adopted to evaluate the dynamic performance of the control system.

The index ITAE, IAE and ISE is expressed as follows [8]:

$$
\begin{aligned}
& \text { ITAE }=\int_{0}^{T} t \mid e(t) d t \\
& I A E=\int_{0}^{T}|e(t)| d t \\
& I S E=\int_{0}^{T} e^{2}(t) d t
\end{aligned}
$$

Table 3. Quantitative comparison between the proposed FLC controllers

\begin{tabular}{cccc}
\hline & & DTC-T1FLC (Hellali, & DTC- \\
& & $2018)$ & T2FLC \\
\hline \multirow{3}{*}{ First Test } & ITAE & 3.232 & 2.526 \\
& $\boldsymbol{I} \boldsymbol{A} \boldsymbol{E}$ & 26.31 & 23.96 \\
& $\boldsymbol{I S E}$ & 2596 & 2423 \\
\multirow{3}{*}{ Second } & $\boldsymbol{I T A \boldsymbol { E }}$ & 34.20 & 34.06 \\
Test & $\boldsymbol{I} \boldsymbol{E} \boldsymbol{E}$ & 42.64 & 40.45 \\
& $\boldsymbol{I S E}$ & 3052 & 2841 \\
\hline
\end{tabular}

ITAE: integral time-weighted absolute error; IAE: Integral 
absolute error; ISE: integral squared error.

For quantitative comparison between two regulators, ITAE, $I A E$ and $I S E$ are used as the criterion. Table. 3 shows the ITAE, $I A E$ and $I S E$ values of direct torque control using two regulators (T1FLC and T2FLC).

This comparison shows clearly that the T2FLC gives good performances and it's more robust than T1FLC.

\section{CONCLUSION}

In this paper, we presented control the doubly star induction machine by direct torque control using a type- 2 fuzzy logic regulator. We established a mathematical model of the machine to study static behavior and dynamic of this machine.

The complete dynamic model of the Direct Torque Control system is developed and simulated by using MATLABSIMULINK. Then, we have continued to improve the direct torque control by the application of type-2 fuzzy logic. The simulation results show that the DTC-T2FLC present a good dynamics performance and his robustness with speed and load torque variation.

\section{REFERENCES}

[1] Tir Z, Soufi Y, Hashemnia MN, Malik OP, Marouani K. (2016). Fuzzy logic field oriented control of double star induction motor drive. Electrical Engineering, 1-9. https://doi.org/10.1007/s00202-016-0377-2

[2] Zhao Y, Lipo TA. (1995). Space vector PWM control of dual three phase induction machine using vector space decomposition. IEEE Transactions on Industry Applications $\quad 31$ 1100-1109. https://doi.org/10.1109/28.464525

[3] Hadiouche D, Razik H, Rezzoug A. (2000). Study and simulation of space vector PWM control of double star induction motors. Power Electronics Congress, 42-47.

[4] Layadi N, Zeghlache S, Benslimane T, Berrabah F. (2017). Comparative analysis between the rotor flux oriented control and backstepping control of a double star induction machine (DSIM) under open-phase fault. AMSE Journals, Series Advances C 72(4): 292-311.

[5] Takahashi I, Noguchi T. (1986). A new quick-response and high efficiency control strategy of an induction motor. IEEE Transactions on Industry Applications 22(5):

820-827.

https://doi.org/10.1109/TIA.1986.4504799

[6] Ghalem B, Bendiabdellah A. (2010). Six-Phase matrix converter fed double star induction motor. Acta Polytechnica Hungarica 7(3).

[7] Radhwane S. (2012). Indirect rotor field-oriented control (IRFOC) of a dual star induction machine (DSIM) using a fuzzy controller. Acta Polytechnica Hungarica 9(4).

[8] Hellali L, Belhamdi S. (2018). Direct torque control of doubly star induction motor using fuzzy logic speed controller. IAES International Journal of Artificial Intelligence (IJ-AI) 7(1): 42-53.

[9] Casadei D, Profumo F, Serra G, Tani A. (2002). FOC and DTC: Two viable schemes for induction motors torque control. IEEE Transactions on Power Electronics 5(17): 779-787. https://doi.org/10.1109/TPEL.2002.802183

[10] Brod MD, Novotny WD. (1985). Current control of VSIPWM inverters. IEEE Transactions on Industry
Applications

IA-21(3):

$562-570$

https://doi.org/10.1109/tia.1985.349711

[11] Mendel JM. (1985). Uncertain rule-based fuzzy logic systems: Introduction and new directions. Prentice-Hall.

[12] Khouidmi H, Massoum A, Meroufel A. (2011). Dual star induction motor drive: Modeling, supplying and control. International Journal of Electrical and Power Engineering 5(1): 28-34.

[13] Wu D, Tan WW. (2006). Genetic learning and performance evaluation of type-2 fuzzy logic controllers. Engineering Applications of Artificial Intelligence 19(8): 829-841. https://doi.org/10.1016/j.engappai.2005.12.011

[14] Hagras H. (2007). Type-2 FLCs: A new generation of fuzzy controllers. IEEE Compute Intelligence Magazine 2(1): 30-43. https://doi.org/10.1109/mci.2007.357192

[15] Wu D, Tan WW. (2006). A simplified type-2 fuzzy controller for real-time control. ISA Transactions 15(4): 503-516. https://doi.org/10.1016/S0019-0578(07)602286

[16] Zaimeddine R, Berkouk EM. (2007). A novel DTC scheme of double-star induction motors using three-level Voltage source inverter. Journal of Engineering and applied Sciences 2(1): 136-142.

[17] Belhamdi S, Goléa A. (2015). Direct torque control for induction motor with broken bars using fuzzy logic type2. AMSE Journals, Series Advances C 70(1-2): 15-28.

[18] Castillo O, Melin P. (2008). A, type-2 fuzzy logic, theory and applications. Granular Computing 223. https://doi.org/10.1007/978-3-540-76284-3

\section{Appendix}

Table 4. Machine parameters [7]

\begin{tabular}{|c|c|c|c|}
\hline $\begin{array}{c}\text { DSIM } \\
\text { Mechanical } \\
\text { Power }\end{array}$ & $\begin{array}{c}4.5 \\
\mathrm{~kW}\end{array}$ & $\begin{array}{c}\text { Stators 1,2 self } \\
\text { inductances }\end{array}$ & $0.022 \mathrm{H}$ \\
\hline Nominal voltage & $\begin{array}{c}220 \\
\mathrm{~V}\end{array}$ & Rotor inductance & $0.006 \mathrm{H}$ \\
\hline Frequency & 50 & $\begin{array}{c}\text { Mutual } \\
\text { inductance }\end{array}$ & $0.3672 \mathrm{H}$ \\
\hline $\begin{array}{c}\text { Pole pair } \\
\text { number }\end{array}$ & 1 & $\begin{array}{c}\text { Moment of } \\
\text { inertia }\end{array}$ & $0.0625 \mathrm{Nms}^{2} / \mathrm{rad}$ \\
\hline $\begin{array}{c}\text { Stators 1,2 } \\
\text { resistances }\end{array}$ & $\begin{array}{c}3.72 \\
\Omega\end{array}$ & $\begin{array}{c}\text { Friction } \\
\text { coefficient }\end{array}$ & $0.001 \mathrm{Nms} / \mathrm{rad}$ \\
\hline Rotor resistance & 2.12 & & \\
\hline
\end{tabular}

List of abbreviations and symbols

\begin{tabular}{|l|l|}
\hline Abbreviations & Designation \\
\hline DSIM & Doubly Star Induction Motor \\
\hline DTC & Direct Torque Control \\
\hline T2FLC & Type-2 Fuzzy Logic Controller \\
\hline T1FLC & Type-1 Fuzzy Logic Controller \\
\hline VSI & Voltage Source Inverter \\
\hline$\Omega_{r}$ & the rotor angular speed \\
\hline$T_{e m}$ & Electromagnetic torque \\
\hline$K_{f}$ & Friction coefficient \\
\hline$J$ & Moment of inertia \\
\hline$P$ & Number of pole pairs \\
\hline$T_{r}$ & Load torque \\
\hline
\end{tabular}

